\title{
Biological effects of rutin on skin aging
}

\author{
SEONG JIN CHOI ${ }^{1 *}$, SUNG-NAE LEE ${ }^{1 *}$, KARAM KIM ${ }^{1}$, DA HYE JOO $^{1}$, SHANGHUN SHIN ${ }^{1}$, JEONGJU LEE $^{1}$, \\ HYUN KYUNG LEE ${ }^{1}$, JIHYUN KIM ${ }^{2}$, SEUNG BIN KWON ${ }^{2}$, MIN JUNG KIM ${ }^{3}$, KYU JOONG AHN ${ }^{3}$, \\ IN-SOOK AN ${ }^{2}$, SUNGKWAN AN ${ }^{1}$ and HWA JUN CHA ${ }^{1}$ \\ ${ }^{1}$ Korea Institute for Skin and Clinical Sciences, Konkuk University, Seoul 143-701; \\ ${ }^{2}$ GeneCellPharm Incorporated, Cheongju-si, Chungcheongbuk-do 361-951; \\ ${ }^{3}$ Department of Dermatology, Konkuk University School of Medicine, Seoul 143-701, Republic of Korea
}

Received August 14, 2015; Accepted May 4, 2016

DOI: 10.3892/ijmm.2016.2604

\begin{abstract}
Rutin, a quercetin glycoside is a member of the bioflavonoid family which is known to possess antioxidant properties. In the present study, we aimed to confirm the anti-aging effects of rutin on human dermal fibroblasts (HDFs) and human skin. We examined the effects of rutin using a cell viability assay, senescence-associated- $\beta$-galactosidase assay, reverse transcription-quantitative polymerase chain reaction, and by measuring reactive oxygen species (ROS) scavenging activity in vitro. To examine the effects of rutin in vivo, rutin-containing cream was applied to human skin. A double-blind clinical study was conducted in 40 subjects aged between 30-50 years and divided into control and experimental groups. The test material was applied for 4 weeks. After 2 and 4 weeks, dermal density, skin elasticity, the length and area of crow's feet, and number of under-eye wrinkles following the application of either the control or the rutin-containing cream were analyzed. Rutin increased the mRNA expression of collagen, type I, alpha $1(C O L 1 A I)$ and decreased the mRNA expression of matrix metallopeptidase 1 (MMPl) in HDFs. We verified that ROS scavenging activity was stimulated by rutin in a dose-dependent manner and we identified that rutin exerted protective effects under conditions of oxidative stress. Furthermore, rutin increased skin elasticity and decreased the length, area and number of wrinkles. The consequences of human aging are primarily visible on the skin, such as increased wrinkling, sagging and decreased elasticity. Overall, this study demonstrated the biological effects of rutin on ROS-induced skin aging.
\end{abstract}

Correspondence to: Dr Hwa Jun Cha, Korea Institute for Skin and Clinical Sciences, Konkuk University, 120 Neungdong-ro, Gwangjin-gu, Seoul 143-701, Republic of Korea

E-mail: hjcha@konkuk.ac.kr

*Contributed equally

Key words: rutin, reactive oxygen species, human dermal fibroblast, aging, extracellular matrix, clinical efficacy

\section{Introduction}

The clinical manifestations of aging are fine wrinkles, thin and transparent skin, loss of underlying fat leading to hollowed cheeks and eye sockets, dry and itchy skin, lack of sufficient perspiration, hair graying, hair loss or hirsutism, and thinning of the nail plates (1). It is widely accepted that intrinsic aging is primarily caused by accumulated damage due to free radicals and by reactive oxygen species (ROS)-induced damage to critical cellular macromolecules (2). Not only does ROS production increase with age but the ability of human skin cells to repair DNA damage steadily decreases over time (3).

ROS play an important role in skin aging. In the skin, about $1.5-5 \%$ of the consumed oxygen is converted into ROS by intrinsic processes (4). ROS are continuously produced as byproducts in the electron transport chain of aerobic metabolism in the mitochondria, and are regarded as the principal cause of intrinsic aging (5). Keratinocytes and fibroblasts are the main producers of mitochondrial ROS in the skin.

Rutin, a quercetin glycoside (6), is a member of the bioflavonoid family also referred to as vitamin P (7). Previous research has identified rutin as an antioxidant with anti-inflammatory, antiallergenic, antiviral, and anticarcinogenic properties, capable of scavenging superoxide radicals (8-13). It has also been demonstrated that rutin is capable of inhibiting human platelet aggregation stimulated by collagen (14), decreasing capillary fragility (15), prolonging activated partial thromboplastin time (16) as well as of exerting anti-thrombotic effects (17).

The present study confirms that rutin reduces skin aging by strengthening dermal density and elasticity through the regulation of enzymes in the extracellular matrix (ECM).

\section{Materials and methods}

Cell culture. Human dermal fibroblasts, (HDFs; Lonza, Basel, Switzerland) were cultured in Dulbecco's modified Eagle medium (Gibco/Life Technologies, Carlsbad, CA, USA), supplemented with $10 \%$ fetal bovine serum (Sigma-Aldrich, St. Louis, MO, USA) and $1 \%$ penicillin/streptomycin (Gibco/Life Technologies) at $37^{\circ} \mathrm{C}$ in an atmosphere of $5 \% \mathrm{CO}_{2}$. Rutin was purchased from Sigma-Aldrich and dissolved in dimethyl sulfoxide. 
Cell viability assay. HDFs were seeded at a density of $3 \times 10^{3}$ cells/ well in a 96-well plate and incubated for $24 \mathrm{~h}$. Rutin $(0-200 \mu \mathrm{M})$ was later added to the cells for $24 \mathrm{~h}$ to measure the cytotoxicity of rutin. To determine the protective effects against oxidative stress, the cells were pre-treated with rutin $(0-100 \mu \mathrm{M})$ for $3 \mathrm{~h}$ and then exposed to $0.2 \mathrm{mM} \mathrm{H}_{2} \mathrm{O}_{2}$ for $24 \mathrm{~h}$. The cytotoxicity of rutin in HDFs was evaluated using a water-soluble tetrazolium salt (WST-1) assay (EZ-Cytox cell viability assay kit; Itsbio, Seoul, Korea). The WST-1 solution was added to cultured cells at a volume equal to $10 \%$ of the culture medium, and then the cells were incubated at $37^{\circ} \mathrm{C}$ for $1 \mathrm{~h}$. Cell viability was evaluated by measuring the absorbance at $450 \mathrm{~nm}$ using an iMark microplate reader (Bio-Rad, Hercules, CA, USA).

Cellular senescence analysis. The expression of lysomal galactosidase as a marker for senescent HDFs was determined using the senescence-associated (SA)- $\beta$-galactosidase staining kit (BioVision, Milpitas, CA, USA) according to the manufacturer's instructions. HDFs were seeded at a density of $2 \times 10^{5}$ cells/well in a $60-\mathrm{mm}$ cell culture plate and incubated until they reached $90 \%$ confluence. Subsequently, the cells were treated with rutin and $\mathrm{H}_{2} \mathrm{O}_{2}$ for $24 \mathrm{~h}$, the medium was removed, and the cells were washed once with phosphate-buffered saline (PBS). A fixing solution $(0.5 \mathrm{ml}$; $4 \%$ formaldehyde and $0.5 \%$ glutaraldehyde in PBS buffer, $\mathrm{pH}$ 7.2) was added to the culture plate for $1 \mathrm{~h}$ in order to fix the cells, and $0.5 \mathrm{ml}$ of a staining solution [staining solution $470 \mu \mathrm{l}$ and $5 \mu \mathrm{l}$ staining supplement, and $20 \mathrm{mg} / \mathrm{ml}$ 5-bromo-4-chloro-3-indolyl- $\beta$-D-galactopyranoside (X-Gal) in $25 \mu \mathrm{l}$ dimethylformamide] for $24 \mathrm{~h}$. The cells then were treated with $1 \mathrm{ml} \mathrm{70 \%} \mathrm{glycerol,} \mathrm{and} \mathrm{images} \mathrm{were} \mathrm{captured} \mathrm{using} \mathrm{an}$ Olympus IX51 microscope (Tokyo, Japan). The percentage of senescent cells was calculated as the senescence ratio [senescent cells $(\%)=$ stained cells/total cells $\mathrm{X} 100]$.

Measurement of ROS scavenging activity. Intracellular ROS formation was measured by adding 2',7'-dichlorofluorescein diacetate (DCF-DA; Sigma-Aldrich). DCF-DA is non-fluorescent until it is hydrolyzed by intracellular esterases and oxidized into the highly fluorescent 2',7'-dichlorofluorescein (DCF) in the presence of ROS. The cells were seeded in 60-mm cell culture plates at a density of $2 \times 10^{5}$ cells/well and incubated for $24 \mathrm{~h}$. Following incubation, the cells were pre-treated with rutin $(0-50 \mu \mathrm{M})$ for $3 \mathrm{~h}$, and then exposed to $0.2 \mathrm{mM} \mathrm{H}_{2} \mathrm{O}_{2}$ for $24 \mathrm{~h}$. After $24 \mathrm{~h}, 10 \mu \mathrm{M}$ DCF-DA was added to the culture media for $30 \mathrm{~min}$, and the medium containing DCF-DA was removed by washing with PBS. The cells were detached from the plates with $1 \%$ trypsin-EDTA and washed with PBS, and ROS was detected by flow cytometry (Becton-Dickinson, Franklin Lakes, NJ, USA).

RNA isolation and reverse transcription-quantitative polymerase chain reaction $(R T-q P C R)$ analysis. Total RNA was isolated using TRIzol reagent (Life Technologies) according to the manufacturer's instructions. The purity and concentration of the RNA were evaluated using MaestroNano ${ }^{\circledR}$, a microspectrophotometer (Maestrogen, Las Vegas, NV, USA). All cDNAs for sensitive and specific miRNA detection were synthesized using the miScript II RT kit (Qiagen, Hilden, Germany) according to the manufacturer's instructions. The following primers were used: collagen, type I, alpha 1 (COLIAI)
COL1A1 forward, 5'-AGGGCCAAGACGAAGACATC-3' and reverse, 5'-AGATCACGTCATCGCACAACA-3'; matrix metalloproteinase $(M M P) 1$ forward, 5'-TCTGACGTTGAT CCCAGAGAGCAG-3' and reverse, 5'-CAGGGTGACACCAG TGACTGCAC-3'. qPCR was performed using EvaGreen dye (Solis BioDyne, Tartu, Estonia) and LineGene K software (Bioer, Hangzhou, China). The CT value for each gene expressed was normalized to that of $\beta$-actin forward, 5'-GGATTCCTA TGTGGGCGACGA-3' and reverse, 5'-CGCTCGGTGA GGATCTTCATG-3'. The $2^{-\Delta \Delta C t}$ method was used to calculate the relative expression level of each gene (6).

Subjects for clinical evaluation. The study protocols were approved by the Institutional Review Board of GeneCellPharm Incorporated (Cheongju-si, Korea). All subjects were informed of the objective of the study and provided informed consent and agreed to use skin care products during the study. Forty women, aged 30-50 years, were selected for a randomized and double-blind clinical trial (control group, 45.50 \pm 5.79 years; experimental group, $45.70 \pm 5.34$ years). The selection of subjects was based on age, signs of skin aging, and being neither pregnant nor nursing. Subjects who presented with symptoms of itching or erythema, or those who hindered the evaluation process due to excessive drinking or smoking were excluded from the experiment. The subjects were divided into control and experimental groups, each containing 20 subjects. All conditions were the same except for the test material used on the experimental group. The study was conducted for 4 weeks. Biometric parameters were measured three times: prior to application, and 2 and 4 weeks after application. During this study, each subject performed a self-evaluation, and using a scale of severity ( 0 , none; 1 , mild; 2 , severe; 3 , very severe), completed a questionnaire to indicate to what extent they exhibited any skin disorders, such as erythema, itching, scaling, edema and tingling and burning sensations, at each visit. The subjects who presented with skin disorders withdrew from the clinical evaluation process.

In order to determine whether the rutin-containing cream had any adverse effects, the subjects were asked individually about the condition of their skin, and a visual evaluation of skin reactions, such as erythema, itching, scaling, tingling, tightness and prickling or burning sensations was performed at each visit. No adverse effects were reported based on either a visual evaluation or the questionnaire (Table I). To examine dermal density, skin elasticity as well as any improvement in wrinkles around the eye, the subjects were instructed to apply $2 \mathrm{~g}$ of test material to the face, including the eye rim, every morning and night for 4 weeks. The subjects and investigators were blinded to the test and control treatments. At each visit, all subjects washed with the cleanser provided and remained quietly in a room with constant temperature $\left(22 \pm 1^{\circ} \mathrm{C}\right)$ and humidity $(45 \pm 5 \%)$ so that all subjects would be evaluated under the same conditions.

The cream was prepared by incorporating the ingredients in the 3 phases $(\mathrm{A}, \mathrm{B}, \mathrm{C})$. The ingredients in the $\mathrm{A}$ phase (distilled water, glycerin, 1,3-butylene glycol) were combined and heated until all the components were melted, and the ingredients in the B phase (distilled water, dipotassium phosphate, sodium hydroxylate, rutin) were combined and heated to the same temperature, to ensure homogeneity. The A and B phase ingredients were combined and emulsified using a homo 
Table I. Abnormal skin reactions reported by subjects.

\begin{tabular}{lclc}
\hline Abnormal reaction & Severity & $\begin{array}{c}\text { Abnormal } \\
\text { reaction }\end{array}$ & Severity \\
\hline Erythema & 0 & Tingling & 0 \\
Swelling (edema) & 0 & Burning & 0 \\
Scaling (epidermis) & 0 & Tightness & 0 \\
Itching & 0 & Prickling & 0 \\
\hline
\end{tabular}

Scale of severity, 0 , none; 1 , mild; 2 , severe; 3 , very severe.

mixer (Tokushu Kika Kogyo Co., Ltd., Japan) at 5,000 rpm for $10 \mathrm{~min}$. The mixture was cooled to $60^{\circ} \mathrm{C}$ and blended with the homogenized phase $\mathrm{C}$ (emulium delta, sepipuls 400) at $5,000 \mathrm{rpm}$ for $10 \mathrm{~min}$. By then, the temperature of the mixture had dropped to $45^{\circ} \mathrm{C}$. The mixture was combined and homogenized, while maintaining the $\mathrm{pH}$ at 6.2 . The cream provided to the experimental group contained $2 \%$ (wt \%) rutin and the cream provided to the control group was prepared using the same volume of water in place of rutin.

Measurement of skin elasticity. To evaluate the improvement in skin elasticity, a DermaLab USB elasticity probe (Cortex Technology ApS, Hadsund, Denmark) was applied and the results were analyzed using the associated application software (version 1.09). Measurements were obtained using a fixed elasticity probe on the left cheek of each subject. To analyze the elasticity measurements, Young's modulus (E) was calculated as a dose-dependent representation of skin elasticity. The measurements of elasticity were taken three times: prior to application, and 2 and 4 weeks after application. The measurement unit is MPa.

Measurement of dermal density. To evaluate dermal density, a DUB SkinScanner (tpm taberna pro medicum $\mathrm{GmbH}$, Lüeneburg, Germany) was used. Dermal density was measured $3 \mathrm{~cm}$ from the left eye, applying a couplant for ultrasonic examination. The analysis range was limited to the area between the dermis and upper panniculus. The measurements were taken three times: prior to application, and 2 and 4 weeks after application.

Measurement of the length and area of crow's feet as well as under-eye wrinkles. To evaluate the extent of improvement in wrinkles, particularly at the eye rim, a Robo skin analyzer CS50 (Inforward Inc., Tokyo, Japan) was used. The facial images were captured from each subject placed in identical positions with equal lighting: on the front, left and right sides of the face. To evaluate improvement, measurements were taken three times: prior to application, and 2 and 4 weeks after application. We analyzed the captured images, matching the facial feature points accurately. The measurement unit of crow's feet length is $\mathrm{mm}$ and area is $\mathrm{mm}^{2}$.

Statistical analysis. In cellular efficacy tests, all results are presented as the mean percentages \pm standard deviation (SD) of three independent experiments. A P-value $<0.05$ as determined by the Student's t-test, was considered statistically


Figure 1. Effects of rutin on cell viability in rutin- and $\mathrm{H}_{2} \mathrm{O}_{2}$-treated human dermal fibroblasts (HDFs). (A) Measurement of cell cytotoxicity of rutin in HDFs. (B) Inhibitory effects of rutin on $\mathrm{H}_{2} \mathrm{O}_{2}$-induced cellular damage response. ${ }^{*} \mathrm{P}<0.05,{ }^{* *} \mathrm{P}<0.01$ and ${ }^{* * * *} \mathrm{P}<0.001$ as determined by the Student's t-test.

significant. In clinical efficacy tests, statistical analyses were conducted using SPSS software (version 17.0 for Windows; IBM, Armonk, NY, USA). Paired t-tests were performed in cases of repeated measurements on the same subject. To analyze subject questionnaires, mean values, SDs, and percentages were used. The formula used to measure the percentage change for each skin parameter was percentage change $=$ [(A-B)/B] $\times 100$, where $\mathrm{A}$ is defined as the individual value of any parameter at the 2 and 4 week visits, and $B$ represents the zero hour of the assessed parameter.

\section{Results}

Cytotoxicity of rutin in HDFs. To determine whether rutin affects the viability of HDFs, cultured HDFs were exposed to concentrations of rutin ranging from $0-200 \mu \mathrm{M}$ for $24 \mathrm{~h}$. Rutin reduced the cell viability of HDFs by $13.23 \%$ at a concentration of $50 \mu \mathrm{M}$ and by $26.05 \%$ at $100 \mu \mathrm{M}$ (Fig. 1A). The cytotoxicity of rutin increased at concentrations $>100 \mu \mathrm{M}$, thus, we used $100 \mu \mathrm{M}$ as the maximum concentration in subsequent experiments (data not shown). To examine the ability of rutin to inhibit cellular damage, we examined cell viability, which increased

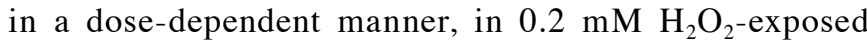
HDFs (Fig. 1B). $\mathrm{H}_{2} \mathrm{O}_{2}$ reduced cell viability to $78.48 \%$; however, following the addition of rutin to the $\mathrm{H}_{2} \mathrm{O}_{2}$-exposed cells, the viability of HDFs increased to 85.53, 91.67, 97.50 and $95.04 \%$ with the addition of $1,10,50$ and $100 \mu \mathrm{M}$ rutin, respectively. 


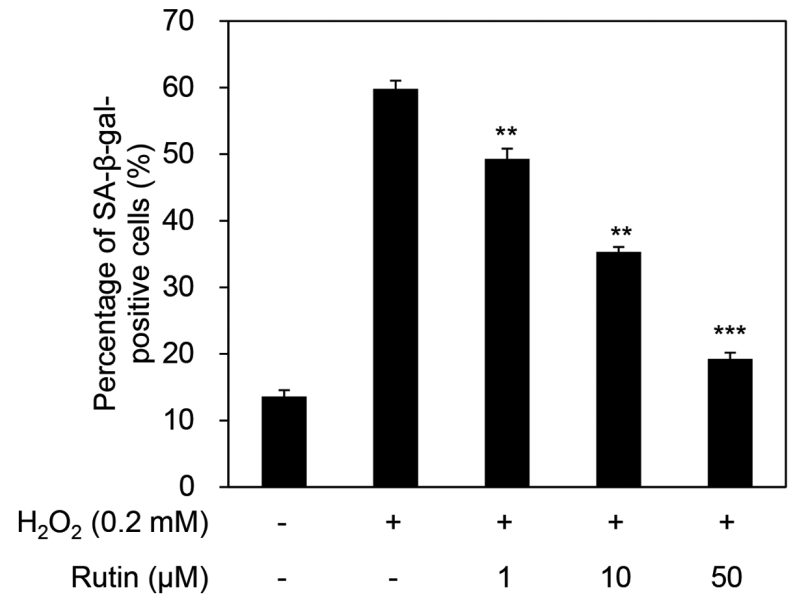

Figure 2. Inhibitory effects of rutin on $\mathrm{H}_{2} \mathrm{O}_{2}$-induced cellular senescence of human dermal fibroblasts (HDFs). ${ }^{* * *} \mathrm{P}<0.01$ and ${ }^{* * * *} \mathrm{P}<0.001$ as determined by the Student's t-test. SA- $\beta$-gal, SA- $\beta$-galactosidase.

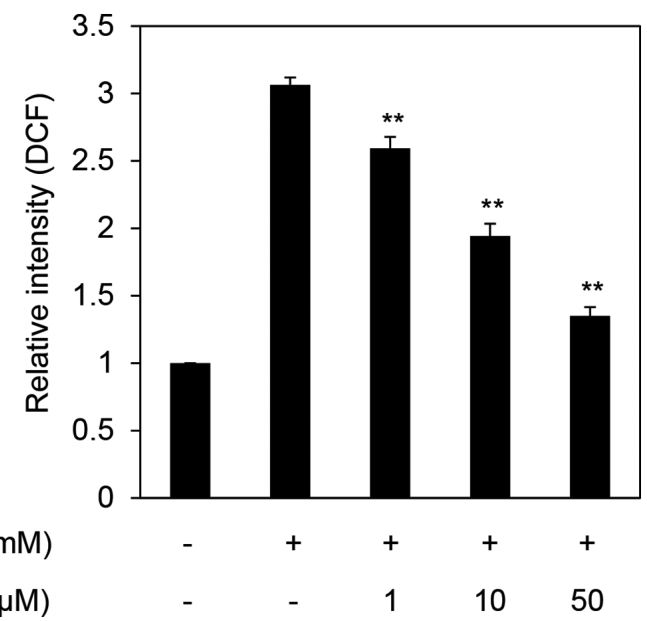

Figure 3. Reactive oxygen species (ROS) scavenging effects of rutin on $\mathrm{H}_{2} \mathrm{O}_{2}-$ treated human dermal fibroblasts (HDFs). ${ }^{* *} \mathrm{P}<0.01$ as determined by the Student's t-test.

Senescent cell detection assay. Next, we examined the inhibition of senescence by rutin using the SA- $\beta$-galactosidase assay. The percentage of senescent cells was $59.80 \%$ in the cells exposed to $\mathrm{H}_{2} \mathrm{O}_{2}$ only. This ratio decreased in a dose-dependent manner to $49.28,35.30$ and $19.26 \%$ with the administration of 1,10 and $50 \mu \mathrm{M}$ rutin (Fig. 2). These results indicate that $\mathrm{H}_{2} \mathrm{O}_{2}$ acts as a stimulator of senescence and that rutin inhibits $\mathrm{H}_{2} \mathrm{O}_{2}$-induced cellular senescence.

Detection of ROS scavenging activity. To determine cellular ROS levels, we performed the DCF-DA assay in $\mathrm{H}_{2} \mathrm{O}_{2}$ - exposed $\mathrm{HDFs}$. The exposure of HDFs to $0.2 \mathrm{mM} \mathrm{H}_{2} \mathrm{O}_{2}$ increased ROS levels $>$ three times that of the control cells. The cells exposed to $0.2 \mathrm{mM} \mathrm{H}_{2} \mathrm{O}_{2}$ and treated with rutin exhibited decreased ROS levels in a dose-dependent manner to a relative intensity of 2.6-, 1.9- and 1.6-fold following treatment with 1, 10 and $50 \mu \mathrm{M}$ rutin (Fig. 3). These results demonstrate that rutin decreases cellular levels of ROS.

Analysis of mRNA expression levels of COL1A1 and MMP1. ROS are known to be inducers of MMPs, which degrade
A

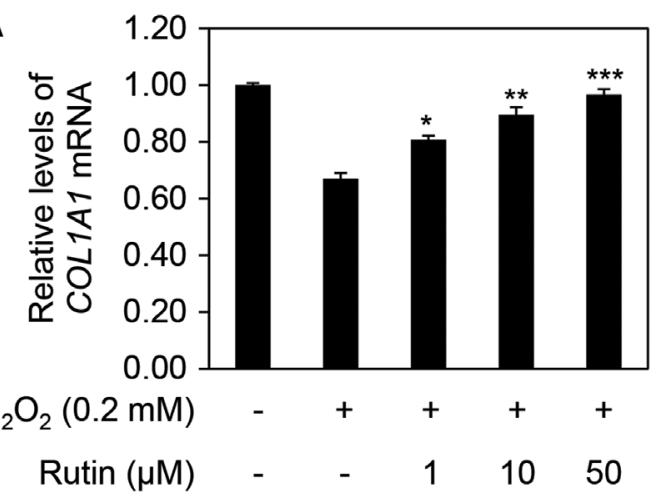

B

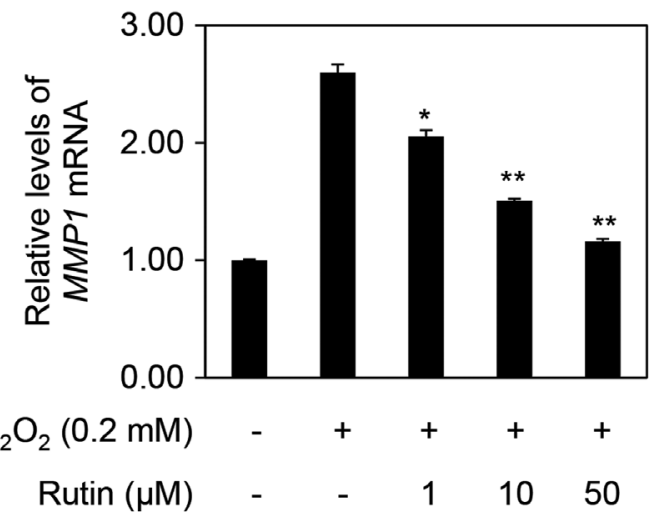

Figure 4. Effects of rutin on the mRNA expression of collagen, type I, alpha $1(C O L 1 A 1)$ and matrix metalloproteinase $1(M M P 1)$ in human dermal fibroblasts (HDFs). Relative mRNA expression levels of (A) COL1A1 and (B) $M M P 1$ in $\mathrm{H}_{2} \mathrm{O}_{2}$ - and rutin-treated HDFs. The results are representative of three independent experiments (means $\pm \mathrm{SD}$ ). ${ }^{*} \mathrm{P}<0.05,{ }^{* *} \mathrm{P}<0.01$ and ${ }^{* * *} \mathrm{P}<0.001$ as determined by the Student's t-test.

intracellular substances $(18,19)$. MMPs are divided into three types: collagenase (MMP1 and MMP8), gelatinase (MMP2 and MMP9), and stromelysin (MMP3); additionally, MMP14 and MMP15 have transmembrane domains which determines their substrate specificity (20-24). MMP1, generated in fibroblasts, is highly present in senescent cells and ultimately decreases collagen degradation (25-33). Collagen, the most abundant protein in the dermis, provides structural support; $>90 \%$ of collagen in the body is type I collagen (34). COL1A1 encodes the major component of type I collagen and its expression level decreased to 0.67 following treatment with $\mathrm{H}_{2} \mathrm{O}_{2}$ compared with no treatment. The relative expression of COL1A1 increased to 0.81, 0.90 and 0.97 in a dose-dependent manner with the addition of 1,10 and $50 \mu \mathrm{M}$ rutin, respectively, compared with $\mathrm{H}_{2} \mathrm{O}_{2}$ alone (Fig. 4A). On the other hand, the expression of $M M P 1$ in the cells exposed to $\mathrm{H}_{2} \mathrm{O}_{2}$ increased to 2.6 compared with that in the untreated cells. However, the relative $M M P 1$ expression decreased to $2.06,1.50$ and 1.16 following treatment with 1,10 and $50 \mu \mathrm{M}$ rutin, respectively (Fig. 4B).

Evaluation of dermal density. As aging occurs, the expression of MMPs is increased which results in the degradation of skin substrate proteins (35). Dermal thickness and density were found to decrease with increasing concentrations of MMPs and degradation of albuminoids and the collagen layer (35). To 


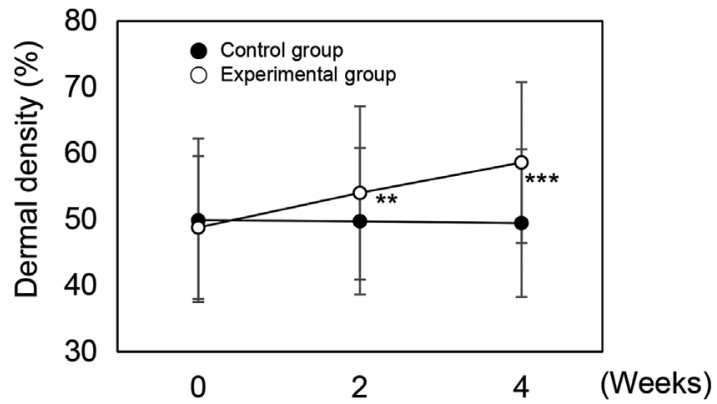

Figure 5. Dermal density of skin to which rutin-containing or control cream was applied. ${ }^{* *} \mathrm{P}<0.05$ and ${ }^{* * * *} \mathrm{P}<0.001$ versus the control group at the same time point as determined by the Student's t-test.

evaluate the clinical efficacy of rutin on aging skin, we demonstrated the effect of cream containing rutin on dermal density. The measurements obtained for the control cream were dermal densities of $49.88 \%$ prior to use, and $49.72 \%$ after 2 weeks and $49.45 \%$ after 4 weeks of use (Fig. 5). The subjects using rutin-containing cream were found to have a dermal density of $48.79 \%$ prior to use, $54.02 \%$ after 2 weeks and $58.62 \%$ after 4 weeks of application (Fig. 5). Dermal density measurements, represented as percentages, are proportional to density. These experimental data were statistically significant $(\mathrm{P}<0.05$ and $\mathrm{P}<0.001)$. To determine the extent of any improvement in skin density, we calculated the improvement as a percentage, based on the value prior to application. Notably, the dermal density improvement rate was $-0.30 \%$ after 2 weeks and $-0.85 \%$ after 4 weeks in the control group. On the other hand, in the experimental group, the improvement rate of dermal density was $10.73 \%$ after 2 weeks and $20.16 \%$ after 4 weeks of use. These results indicate that rutin increases dermal thickness.

Evaluation of length and area of crow's feet. Wrinkles, a representative aging phenomenon, occur in response to structural alterations of cells and tissues. Wrinkles arising due to intrinsic aging are formed by decreases in collagen and elasticity, denaturalization of elastic fibers and the stratum corneum, and a loss of skin moisture (36). Wrinkles arising from extrinsic aging are formed by ROS, which damage lipids and proteins in the skin, through the production of inflammatory cytokines $(27,37)$. Previous research has found that ROS reduce collagen and elastin synthesis and are a major cause of wrinkle formation as a result of increased protease activities in various cellular signal transduction systems (38). Thus, we examined whether rutin may potentially be used as an anti-wrinkle ingredient in creams through clinical efficacy experiments.

The length of crow's feet were $63.50 \mathrm{~mm}$ prior to application, $64.25 \mathrm{~mm}$ after 2 weeks, and $64.95 \mathrm{~mm}$ after 4 weeks in the control group (Fig. 6A). In the experimental group, lengths were $68.40 \mathrm{~mm}$ prior to application, and $59.20 \mathrm{~mm}$ after 2 weeks and $52.05 \mathrm{~mm}$ after 4 weeks of application (Fig. 6A). The measured values of the experimental group were statistically significant $(\mathrm{P}<0.05$ and $\mathrm{P}<0.001)$. To compare improvements in the length of crow's feet between the control and experimental groups, we analyzed the data over time. In the control group, improvement rates were $-1.18 \%$ after 2 weeks and $-2.28 \%$ after 4 weeks application. In the experimental group, improvement rates were $13.45 \%$ after 2 weeks and $23.90 \%$ after 4 weeks of
A

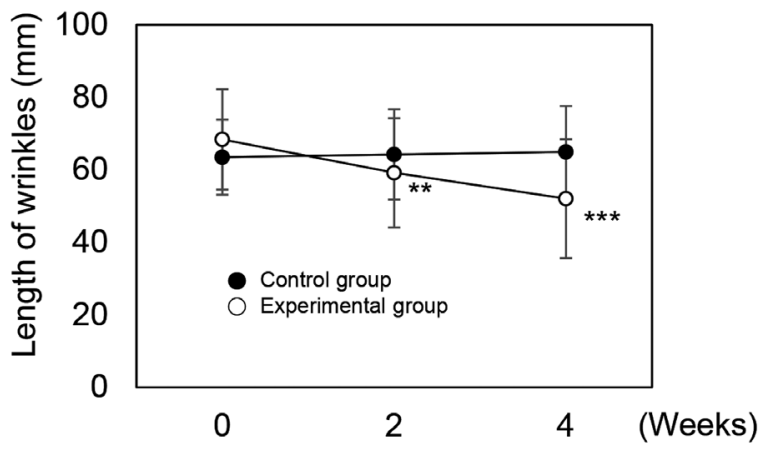

B

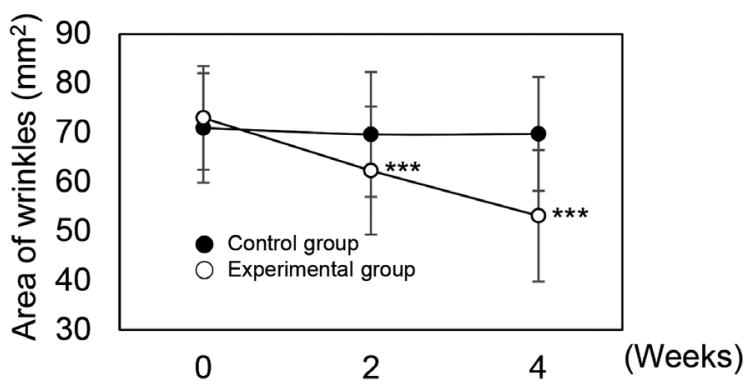

C

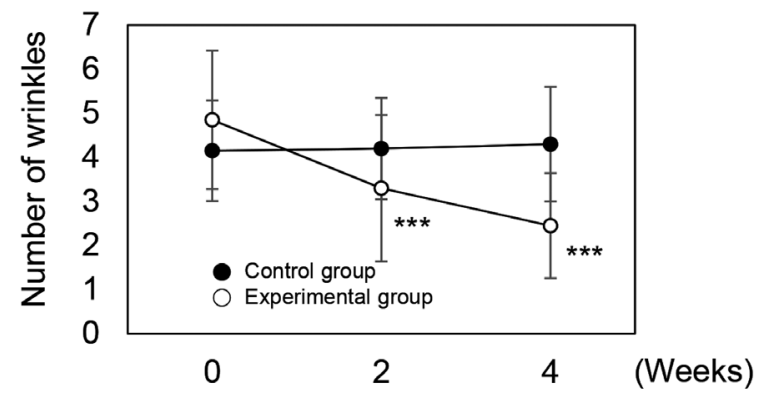

Figure 6. Beneficial effects of rutin-containing cream on eye wrinkles. The measurements of the (A) length and (B) area of crow's feet. (C) Measurements of wrinkle number under the eye rim. ${ }^{* *} \mathrm{P}<0.05$ and ${ }^{* * *} \mathrm{P}<0.001$ versus the control group at the same time point as determined by the Student's t-test.

use. From these results, we confirmed the effects of rutin on wrinkle improvement.

In the control group, the area affected by crow's feet was $70.95 \mathrm{~mm}^{2}$ prior to application, and $69.65 \mathrm{~mm}^{2}$ after 2 weeks and $69.75 \mathrm{~mm}^{2}$ after 4 weeks of use (Fig. 6B). In the experimental group, the area affected by crow's feet was $73.00 \mathrm{~mm}^{2}$ before application, and $62.30 \mathrm{~mm}^{2}$ after 2 weeks and $53.15 \mathrm{~mm}^{2}$ after 4 weeks of application (Fig. 6B). The experimental group results were statistically significant $(\mathrm{P}<0.001)$.

The use of rutin-containing cream significantly reduced the areas affected by crow's feet over time. In the control group, the improvement rates were $-1.83 \%$ after 2 weeks and $1.69 \%$ after 4 weeks. The improvement rates in the experimental group were $14.66 \%$ after 2 weeks and $27.19 \%$ after 4 weeks. From these results, we again confirmed the effects of rutin on wrinkle improvement.

Evaluation of under-eye wrinkles. In the control group, the average number of under-eye wrinkles was 4.15 prior to application, 4.20 after 2 weeks, and 4.30 after 4 weeks (Fig. 6C). In the experimental group, the number of under-eye wrinkles was 


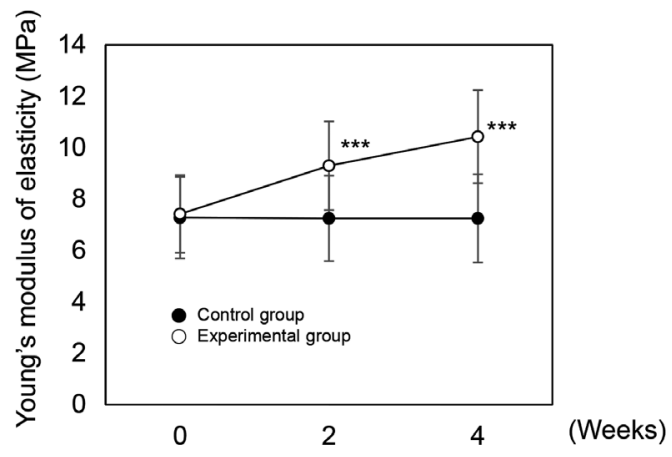

Figure 7. Effects on Young's modulus of skin elasticity of rutin-containing cream applied over time. ${ }^{* * *} \mathrm{P}<0.001$ versus the control group at the same time point as determined by the Student's t-test.

4.85 before application, and 3.30 after 2 weeks and 2.45 after 4 weeks application (Fig. 6C). The measured values of the experimental group were statistically significant $(\mathrm{P}<0.001)$.

We then assessed the improvement in under-eye wrinkles over time. In the control group, improvements were $-1.20 \%$ after 2 weeks and $-3.61 \%$ after 4 weeks application. Improvement rates in the experimental group were $31.96 \%$ after 2 weeks and $49.48 \%$ after 4 weeks. From these results, we confirmed the effects of rutin on wrinkle improvement.

Evaluation of skin elasticity. The dermis is composed of ECM that contains fibrous proteins such as collagen and elastin. Dermal fibroblasts regulate skin elasticity (39). Factors, such as ROS, ultraviolet (UV) rays or age, cause skin damage, wrinkle formation, and decreased skin elasticity by degrading collagen and elastin $(39,40)$. In this study, we examined the effects of rutin on skin elasticity. In the control group, elasticity was 7.28 before application, and 7.25 after 2 weeks and 7.25 after 4 weeks application. In the experimental group, elasticity was 7.42 before application, and 9.30 after 2 weeks and 10.43 after 4 weeks of use (Fig. 7). The experimental group results were statistically significant $(\mathrm{P}<0.001)$. To compare the improvement in skin elasticity between the control and experimental groups, we analyzed the measured data over time. In the control group, improvements were $-0.41 \%$ after 2 weeks and $-0.48 \%$ after 4 weeks application. Improvement rates in the experimental group were $25.34 \%$ after 2 weeks and $40.50 \%$ after 4 weeks. From these results, we confirmed the beneficial effects of rutin on elasticity. All subjects had no adverse effects following a self-evaluation to determine the presence of any skin disorders (Table I).

\section{Discussion}

The present study examined the antioxidant and anti-aging effects as well as the beneficial effects of rutin on skin barrier function through cellular and clinical efficacy experiments. The results of cellular experiments on HDFs indicated the antioxidant and anti-aging effects of rutin. In HDFs, rutin protects cells against damage induced by $\mathrm{H}_{2} \mathrm{O}_{2}$. Furthermore, we identified a ROS scavenging effect of rutin by DCF-DA assay and reduced $\mathrm{H}_{2} \mathrm{O}_{2}$-induced cellular senescence. After analyzing the expression of $M M P 1$ and $C O L 1 A 1$, we verified that rutin reduces $M M P 1$ expression and increases COLIAl expression. Notably, cutaneous elasticity was reported to be the composite result of the amount of elastic fibers and ECM-filling materials $(41,42)$. Additionally, MMPs are known to degrade all components of the ECM, such collagen, elastin, fibronectin, proteoglycans and laminin $(34,43,44)$. Thus, MMP expression not only impairs procollagen synthesis and degrades the ECM, but leads to a loss of elasticity and skin dryness $(45,46)$. Thus, we conducted experiments to determine the clinical efficacy of rutin.

We first manufactured rutin-containing cream. The clinical efficacy tests were conducted with 40 subjects, women between 30-50 years of age, selected for a randomized and double-blind study. The subjects were divided into two groups, experimental and control, and $2 \%$ rutin-containing or basic cream were applied, respectively. Dermal density improved $10.73 \%$ after 2 weeks and $20.16 \%$ after 4 weeks of application of the rutin-containing cream in the experimental group. We also showed that rutin-containing cream improved skin elasticity $25.34 \%$ after 2 weeks and $40.50 \%$ after 4 weeks of application. Reduced skin elasticity contributes to damaged skin structure and aging, particularly wrinkle formation (47-50). Thus, we investigated the length, area and number of wrinkles around the eyes of the rutin-treated subjects.

The length of crow's feet improved by $13.45 \%$ after 2 weeks and $23.90 \%$ after 4 weeks. Additionally, the area of crow's feet improved by $14.66 \%$ after 2 weeks and $27.19 \%$ after 4 weeks. After analyzing the average number of under-eye wrinkles, we demonstrated the effects of rutin on facial wrinkles. The number of under-eye wrinkles improved by $31.96 \%$ after 2 weeks and $49.48 \%$ after 4 weeks. These results indicate that rutin improves skin dermal density, reduces fine winkles, and enhances elasticity. We suggest that rutin may be used as a major ingredient in anti-aging cosmetics in order to improve skin elasticity and reduce wrinkles.

\section{Acknowledgements}

The present study was supported by the KU Research Professor Program (H.-J.C.) of Konkuk University. This study was also supported by grants from the Ministry of Science, ICT and Future Planning (no. 20110028646), the Korean Health Technology R\&D Project, Ministry of Health and Welfare (grant no. HN13C0075), and the Ministry of Oceans and Fisheries (no. OF123321) of Republic of Korea.

\section{References}

1. Zouboulis $\mathrm{CC}$ and Makrantonaki E: Clinical aspects and molecular diagnostics of skin aging. Clin Dermatol 29: 3-14, 2011.

2. Beckman KB and Ames BN: The free radical theory of aging matures. Physiol Rev 78: 547-581, 1998.

3. Pons B, Belmont AS, Masson-Genteuil G, Chapuis V, Oddos T and Sauvaigo S: Age-associated modifications of Base Excision Repair activities in human skin fibroblast extracts. Mech Ageing Dev 131: 661-665, 2010.

4. Poljšak B, Dahmane RG and Godić A: Intrinsic skin aging: the role of oxidative stress. Acta Dermatovenerol Alp Pannonica Adriat 21: 33-36, 2012.

5. Farage MA, Miller KW, Elsner P and Maibach HI: Intrinsic and extrinsic factors in skin ageing: a review. Int J Cosmet Sci 30: 87-95, 2008.

6. Kim KH, Lee KW, Kim DY, Park HH, Kwon IB and Lee HJ: Optimal recovery of high-purity rutin crystals from the whole plant of Fagopyrum esculentum Moench (buckwheat) by extraction, fractionation, and recrystallization. Bioresour Technol 96: 1709-1712, 2005 
7. Wagner C, Fachinetto R, Dalla Corte CL, Brito VB, Severo D, de Oliveira Costa Dias G, Morel AF, Nogueira CW and Rocha JB: Quercitrin, a glycoside form of quercetin, prevents lipid peroxidation in vitro. Brain Res 1107: 192-198, 2006.

8. La Casa C, Villegas I, Alarcón de la Lastra C, Motilva V and Martín Calero MJ: Evidence for protective and antioxidant properties of rutin, a natural flavone, against ethanol induced gastric lesions. J Ethnopharmacol 71: 45-53, 2000.

9. Kamalakkannan N and Prince PS: Antihyperglycaemic and antioxidant effect of rutin, a polyphenolic flavonoid, in streptozotocin-induced diabetic Wistar rats. Basic Clin Pharmacol Toxicol 98: 97-103, 2006

10. Bishnoi M, Chopra K and Kulkarni SK: Protective effect of rutin, a polyphenolic flavonoid against haloperidol-induced orofacial dyskinesia and associated behavioural, biochemical and neurochemical changes. Fundam Clin Pharmacol 21: 521-529, 2007.

11. Makino T, Kanemaru M, Okuyama S, Shimizu R, Tanaka H and Mizukami H: Anti-allergic effects of enzymatically modified isoquercitrin ( $\alpha$-oligoglucosyl quercetin 3-O-glucoside), quercetin 3-O-glucoside, $\alpha$-oligoglucosyl rutin, and quercetin, when administered orally to mice. J Nat Med 67: 881-886, 2013.

12. Han Y, Ding Y, Xie D, Hu D, Li P, Li X, Xue W, Jin L and Song B: Design, synthesis, and antiviral activity of novel rutin derivatives containing 1, 4-pentadien-3-one moiety. Eur J Med Chem 92: 732-737, 2015.

13. Perk AA, Shatynska-Mytsyk I, Gerçek YC, Boztaş K, Yazgan M, Fayyaz S and Farooqi AA: Rutin mediated targeting of signaling machinery in cancer cells. Cancer Cell Int 14: 124, 2014.

14. Sheu JR, Hsiao G, Chou PH, Shen MY and Chou DS: Mechanisms involved in the antiplatelet activity of rutin, a glycoside of the flavonol quercetin, in human platelets. J Agric Food Chem 52: 4414-4418, 2004.

15. MacLean AL and Brambel CE: Dicumarol and rutin in vascular disorders. Trans Am Ophthalmol Soc 44: 194-213, 1946.

16. Kuntić V, Filipović I and Vujić Z: Effects of rutin and hesperidin and their $\mathrm{Al}(\mathrm{III})$ and $\mathrm{Cu}(\mathrm{II})$ complexes on in vitro plasma coagulation assays. Molecules 16: 1378-1388, 2011.

17. Choi JH, Kim DW, Park SE, Lee HJ, Kim KM, Kim KJ, Kim MK, Kim SJ and Kim S: Anti-thrombotic effect of rutin isolated from Dendropanax morbifera Leveille. J Biosci Bioeng 120: 181-186, 2015.

18. Jing Y, Dai J, Chalmers-Redman RM, Tatton WG and Waxman S: Arsenic trioxide selectively induces acute promyelocytic leukemia cell apoptosis via a hydrogen peroxide-dependent pathway. Blood 94: 2102-2111, 1999.

19. Jabs T: Reactive oxygen intermediates as mediators of programmed cell death in plants and animals. Biochem Pharmacol 57: 231-245, 1999.

20. Woessner JF Jr: Matrix metalloproteinases and their inhibitors in connective tissue remodeling. FASEB J 5: 2145-2154, 1991.

21. Sato H, Takino T, Okada Y, Cao J, Shinagawa A, Yamamoto E and Seiki M: A matrix metalloproteinase expressed on the surface of invasive tumour cells. Nature 370: 61-65, 1994.

22. Will $\mathrm{H}$ and Hinzmann B: cDNA sequence and mRNA tissue distribution of a novel human matrix metalloproteinase with a potential transmembrane segment. Eur J Biochem 231: 602-608, 1995.

23. Matrisian LM: The matrix-degrading metalloproteinases. BioEssays 14: 455-463, 1992.

24. Matrisian LM: Metalloproteinases and their inhibitors in matrix remodeling. Trends Genet 6: 121-125, 1990.

25. Burke EM, Horton WE, Pearson JD, Crow MT and Martin GR Altered transcriptional regulation of human interstitial collagenase in cultured skin fibroblasts from older donors. Exp Gerontol 29: 37-53, 1994.

26. Bizot-Foulon V, Bouchard B, Hornebeck W, Dubertret L and Bertaux B: Uncoordinate expressions of type I and III collagens, collagenase and tissue inhibitor of matrix metalloproteinase 1 along in vitro proliferative life span of human skin fibroblasts. Regulation by all-trans retinoic acid. Cell Biol Int 19: 129-135, 1995 .

27. Fisher GJ, Wang ZQ, Datta SC, Varani J, Kang S and Voorhees JJ: Pathophysiology of premature skin aging induced by ultraviolet light. N Engl J Med 337: 1419-1428, 1997.

28. Vincenti MP, White LA, Schroen DJ, Benbow U and Brinckerhoff CE: Regulating expression of the gene for matrix metalloproteinase-1 (collagenase): mechanisms that control enzyme activity, transcription, and mRNA stability. Crit Rev Eukaryot Gene Expr 6: 391-411, 1996.

29. Westermarck J and Kähäri VM: Regulation of matrix metalloproteinase expression in tumor invasion. FASEB J 13: 781-792, 1999.
30. White LA and Brinckerhoff CE: Two activator protein-1 elements in the matrix metalloproteinase-1 promoter have different effects on transcription and bind Jun D, c-Fos, and Fra-2. Matrix Biol 14. 715-725, 1995

31. White LA, Maute C and Brinckerhoff CE: ETS sites in the promoters of the matrix metalloproteinases collagenase (MMP-1) and stromelysin (MMP-3) are auxiliary elements that regulate basal and phorbol-induced transcription. Connect Tissue Res 36: 321-335, 1997.

32. Karin M, Liu Z and Zandi E: AP-1 function and regulation. Curr Opin Cell Biol 9: 240-246, 1997.

33. Angel P, Szabowski A and Schorpp-Kistner M: Function and regulation of AP-1 subunits in skin physiology and pathology. Oncogene 20: 2413-2423, 2001

34. Lim JY, Kim OK, Lee J, Lee MJ, Kang N and Hwang JK: Protective effect of the standardized green tea seed extract on UVB-induced skin photoaging in hairless mice. Nutr Res Pract 8: 398-403, 2014.

35. Nwomeh BC, Liang HX, Diegelmann RF, Cohen IK and Yager DR: Dynamics of the matrix metalloproteinases MMP-1 and MMP-8 in acute open human dermal wounds. Wound Repair Regen 6: 127-134, 1998.

36. Parrado J, Bougria M, Ayala A, Castaño A and Machado A: Effects of aging on the various steps of protein synthesis: fragmentation of elongation factor 2. Free Radic Biol Med 26 : 362-370, 1999 .

37. Fisher GJ, Kang S, Varani J, Bata-Csorgo Z, Wan Y, Datta S and Voorhees JJ: Mechanisms of photoaging and chronological skin aging. Arch Dermatol 138: 1462-1470, 2002.

38. Berneburg M and Krutmann J: Photoaging-associated largescale deletions of mitochondrial DNA. Methods Enzymol 319: 366-376, 2000

39. Rossetti D, Kielmanowicz MG, Vigodman S, Hu YP, Chen N, Nkengne A, Oddos T, Fischer D, Seiberg M and Lin CB: A novel anti-ageing mechanism for retinol: induction of dermal elastin synthesis and elastin fibre formation. Int J Cosmet Sci 33: 62-69, 2011.

40. Hachiya A, Sriwiriyanont P, Fujimura T, Ohuchi A, Kitahara T, Takema Y, Kitzmiller WJ, Visscher MO, Tsuboi R and Boissy RE: Mechanistic effects of long-term ultraviolet B irradiation induce epidermal and dermal changes in human skin xenografts. Am J Pathol 174: 401-413, 2009.

41. Sherratt MJ: Tissue elasticity and the ageing elastic fibre. Age (Dordr) 31: 305-325, 2009.

42. Tracy LE, Minasian RA, Caterson EJ: Extracellular matrix and dermal fibroblast function in the healing wound. Adv Wound Care (New Rochelle) 5: 119-136, 2016

43. Inomata S, Matsunaga Y, Amano S, Takada K, Kobayashi K, Tsunenaga M, Nishiyama T, Kohno Y and Fukuda M: Possible involvement of gelatinases in basement membrane damage and wrinkle formation in chronically ultraviolet B-exposed hairless mouse. J Invest Dermatol 120: 128-134, 2003.

44. Cho S, Won CH, Lee DH, Lee MJ, Lee S, So SH, Lee SK, Koo BS, Kim NM and Chung JH: Red ginseng root extract mixed with Torilus fructus and Corni fructus improves facial wrinkles and increases type I procollagen synthesis in human skin: a randomized, double-blind, placebo-controlled study. J Med Food 12: 1252-1259, 2009

45. Manosroi A, Chutoprapat R, Abe M, Manosroi W and Manosroi J: Anti-aging efficacy of topical formulations containing niosomes entrapped with rice bran bioactive compounds. Pharm Biol 50: 208-224, 2012.

46. Kligman LH and Kligman AM: The nature of photoaging: its prevention and repair. Photodermatol 3: 215-227, 1986.

47. Hussain SH, Limthongkul B and Humphreys TR: The biomechanical properties of the skin. Dermatol Surg 39: 193-203, 2013.

48. Roh E, Kim JE, Kwon JY, Park JS, Bode AM, Dong Z and Lee KW: Molecular mechanisms of green tea polyphenols with protective effects against skin photoaging. Crit Rev Food Sci Nutr: Jun 26, 2015 (Epub ahead of print).

49. Talwar HS, Griffiths CE, Fisher GJ, Hamilton TA and Voorhees JJ: Reduced type I and type III procollagens in photodamaged adult human skin. J Invest Dermatol 105: 285-290, 1995.

50. Fisher GJ and Voorhees JJ: Molecular mechanisms of photoaging and its prevention by retinoic acid: ultraviolet irradiation induces MAP kinase signal transduction cascades that induce Ap-1-regulated matrix metalloproteinases that degrade human skin in vivo. J Investig Dermatol Symp Proc 3: 61-68, 1998. 